\title{
Important aspects of home care service: An interview study of persons with dementia
}

2020, Vol. 0(0) I-15

(C) The Author(s) 2020

Article reuse guidelines:

sagepub.com/journals-permissions DOI: $10.1177 / 147 \mid 301220964393$ journals.sagepub.com/home/dem

(SAGE

\section{Marie Olsen}

School of Education, Health and Social Studies, Dalarna University, Falun, Sweden; Department of Neurobiology, Care Sciences and Society, Division of Nursing, Karolinska Institute and Stockholm University, Stockholm, Sweden

\section{Camilla Udo}

School of Education, Health and Social Studies, Dalarna University, Sweden; Center for Clinical Research, Dalarna, Sweden; Department of Health Care Sciences, Palliative Research Centre, Ersta Sköndal Bräcke University College, Stockholm, Sweden

\section{Anne-Marie Boström}

Department of Neurobiology, Care Sciences and Society, Division of Nursing, Karolinska Institute, Sweden; Theme Ageing, Karolinska University Hospital, Huddinge, Sweden; Stockholms Sjukhem, R\&D Unit, Stockholm, Sweden

\section{Lena Marmstål Hammar}

School of Health, Care, and Social Welfare, Mälardalen University, Sweden; School of Education, Health and Social Studies, Dalarna University, Sweden; Department of Neurobiology, Care Sciences and Society, Division of Nursing, Karolinska Institute, Sweden

\begin{abstract}
Background and Aim: Because of the policy of 'ageing in place' and a decreasing number of beds in residential settings, more persons with dementia live at home with support from home care services. However, previous studies have revealed more unmet needs and a lower quality of life in this group than in other groups. Because few qualitative studies are performed in which persons with dementia have the opportunity to tell their own stories and describe what they find important, this study aimed to interview persons with dementia and describe their views on the important aspects of receiving home care service. Methods: The study used a qualitative approach, and I 4 persons with dementia participated in the interviews. The interviews were analysed using qualitative content analysis.
\end{abstract}

\section{Corresponding author:}

Marie Olsen, School of Education, Health and Social Studies, Dalarna University, Falun 791 88, Sweden.

Email: moe@du.se 
Findings: The findings revealed one overarching theme. The importance of being supported as a unique and capable human, that is the persons with dementia stated that despite their dementia diagnoses, it was important to be seen as a person with capabilities, although in need of support. This theme was built on three subthemes: being seen as a person, being informed and involved, and being part of a relationship. Conclusions: Our study showed that persons with dementia are able to express, formulate and reflect on their needs and preferences about their daily care as well as what is important to them when receiving home care service. Therefore, their point of view should be taken into consideration when planning, providing and evaluating care.

\section{Keywords}

dementia, home care service, interview, experiences, person-centred care

\section{Background}

In line with the 'ageing in place' policy, most people with dementia continue to live at home, and this is a fundamental principle in the care of older people in Sweden and internationally (Wiles et al., 2012). Ageing in place favours the case in which older people, including persons with dementia (Kerpershoek et al., 2018), age at home for as long as possible, regardless of frailty, impairment and complex and diverse needs for services, and institutionalisation is delayed (SBU [Swedish Agency for Health Technology Assessment and Assessment of Social Services], 2019; Schon et al., 2016).

In Sweden, home care service (HCS) includes services and personal care. For example services involve domestic cleaning, shopping, laundry, cooking and meals on wheels. Personal care refers to meeting physical, mental and social needs, such as eating and drinking, bathing and getting dressed (Sandberg et al., 2019; Szebehely \& Trydegard, 2012). In Sweden, HCS is primarily provided by assistant nurses, meaning those who have completed 1 year of nursing education, or by nursing assistants, who have had no formal nursing education (Hallberg et al., 2016; SBU, 2019). Persons in need of health care may also receive municipal home health care (HHC) which includes medical measures, nursing and rehabilitation, is regulated by the Health and Medical Services Act (SFS 2017: 30) and is provided by registered healthcare professionals such as registered nurses, occupational therapists, and physiotherapists. Assistant nurses may get delegation from a registered healthcare personnel in, for example medical administration regulated by the Patient Safety Act (2010:659).

The municipalities have the responsibility to care for older people, that is HCS and institutional care are regulated by the Swedish Social Services Act, which emphasises living independently under safe conditions and having an active and meaningful life in the community with others (SFS 2001: 453). Furthermore, national fundamental values were introduced in the Swedish law to guarantee such care for older people and to ensure the dignified life and well-being of older people (Government Preposition 2009/2010:116). These fundamental values constitute a code that staff are obliged to follow, which emphasises each person's right to personal respect, privacy, bodily integrity, self-determination and participation (SOSFS 2012:3). These values have a clear link to person-centred care (PCC), which has become a standard for high-quality care, particularly in the care of persons with dementia (Manthorpe \& Samsi, 2016; Ruggiano \& Edvardsson, 2013). In addition, the Swedish national guidelines for the care of persons with dementia state that care should be person-centred National Board of Health and Welfare (NBHW) (2017).

The provision of PCC is based on a relationship between the care recipient and the carer which includes respect for the person's uniqueness, respect of personal preferences and support for selfdetermination (McCance et al., 2011; McCormack, 2016). PCC places less emphasis on care tasks 
and more on the person (McCormack \& McCance, 2016). However, NBHW (2017), along with previous research (Bökberg et al., 2015; Hallberg et al., 2016; Jennings et al., 2019; Karlsson et al., 2015; Rapaport et al., 2018), states that knowledge about dementia and how to best provide care for persons with dementia is lacking in all professional groups working in social services. When knowledge is lacking, this commonly results in a task-orientated approach instead of a personcentred approach (Bing-Jonsson et al., 2016).

Studies involving persons with dementia in HCS are sparse, but there are some. A recent study by Mazurek et al. (2019) found that unmet needs of persons with dementia were related to activities of daily living, psychological distress and a need for company. Black et al. (2019) found unmet needs related to safety, general health and daily activities, which were correlated with more neuropsychiatric symptoms and lower quality of life (QoL). On contrary, Harrison et al. (2019) found that persons with dementia in HCS experience a higher QoL and greater social connection in comparison with persons with dementia in residential living.

There is a growing demand for home care with a focus on dementia care; people with dementia living at home do not receive the support they need from HCS because there is a knowledge gap regarding how to design and deliver evidence-based services to support people with dementia living at home (NBHW, 2017). To improve and develop HCS, it is important to listen to those who are actually concerned - the care receivers - and research that directly involves people with dementia is crucial (Morbey et al., 2019). Thus, despite intellectual disabilities, it is crucial in dementia care to invite persons with dementia to participate in research and let their voices be heard (Morrisby et al., 2018; Rapaport et al., 2018). In the context of HCS in Sweden, to our knowledge, no studies have focussed on important aspects of care described by persons with dementia. Therefore, this study aimed to describe the views of persons with dementia regarding important aspects of receiving HCS.

\section{Method}

\section{Design}

This study used a qualitative approach with semi-structured interviews as the data collection method.

\section{Setting and participants}

The study was conducted in a municipality in a rural area of Sweden with approximately 60,000 inhabitants. In this municipality, HCS is delivered by both public and private providers, with most being public providers. The participants consisted of a convenience sample $(n=14)$ of persons with dementia recruited from three different day-care centres for persons with dementia, where a total of 58 persons with dementia were enrolled.

The participants were recruited through the head of the unit for day-care centres based on the following inclusion criteria: aged 65 years or more, diagnosed with dementia, able to speak Swedish or English, capable of conversation, living at home, receiving HCS and having the capacity to consent to participation. The head of the unit and the staff in the day-care centres explained the study, extended an invitation to participate and with person's permission shared their contact details with the first author. All individuals interested in participating received a written information to inform and consult their next of kin regarding participation in the study. To establish contact and build trust with those who had given their initial oral consent to the staff, the first author spent two half days at each day-care centre a few days before the actual interviews. During the last visit, the first author also set up the interview time with those who already have given their written consent to participate by themselves $(n=14)$ or by their next of kin $(n=3)$ and once again obtained informed consent. 
All the persons with dementia who received information about the study fit the inclusion criteria. Initially, 17 participants expressed a desire to participate; however, three persons (two men and one woman) later declined to participate when the actual interview was to be conducted. The reason for declining was that they were occupied with other activities. Thus, in the end, 14 persons with dementia participated in an individual face-to-face interview that was held in a quiet room at the daycare centre. Of the 14 persons interviewed, 12 were women and two were men, aged 71-92 years, with a mean age of 82 years. Twelve received HCS from a public provider and two from a private provider. 11 were living alone, and three were living with their spouses.

\section{Data collection}

Data were collected using semi-structured in-depth interviews (Polit \& Beck, 2016) by the first author (MO). Based on the aim of the study, an interview guide with follow-up questions and probes was developed (Table 1). The use of a semi-structured interview guide allowed the researchers to

Table I. Interview questions.

Can you describe the help you have received from home care services?

What was important when you applied to receive home care services?

Did you receive the help you needed?

Describe how it felt to receive home care services

Was it what you had expected?

Did you find something more difficult/easier than you had thought it would be?

If you did find something more difficult/easier, has this changed or is it still difficult/easy?

Can you describe what you consider to be good home care services?

For home care services to work well for you, what is important?

Can you give examples of when home care services worked well/did not work well?

Why did things work well/not work well?

What values do you think home care services need to hold?

Can you give examples?

When you do not get the help that is important to you, can you explain how you and your situation are affected?

Can you give examples?

Have you received help with something that is not important to you? Can you explain why it is not important?

Can you give examples?

Can you describe how you receive your help?

What works well? What does not work well?

Can you give examples?

Is it important to you how you get your help?

Why is important?

Do home care services have characteristics that are particularly important to you?

What are these characteristics?

Why are these not important? In what way?

Can you give some examples?

What is lacking among these characteristics?

Can you explain how you and your situation would be affected if any of the characteristics you think are important were lacking?

Can you give examples when these characteristics were lacking?

Can you explain how this affected you and your situation? 
move from broad, open-ended questions to more specific questions (Polit \& Beck, 2016). Because of the dementia-related symptoms of the participants, the interviewer commonly had to clarify or rephrase the questions. For example initially, when some of the participants said that they did not receive HCS, the first author asked about the person who comes and helps them, which helped the participants understand and answer the question. Where required, each answer was followed up by further probes, such as 'Can you explain this further?' or 'Could you please give an example?' The interviews lasted between 25 and 45 minutes, the mean length was 39 minutes, and the interviews were digitally recorded and transcribed verbatim.

\section{Data analysis}

The transcribed interviews were analysed using the latent content analysis technique described by Graneheim and Lundman (2004) with the following steps: (1) The interviews were read to obtain an overall understanding of the text. (2) Sentences of paragraphs related to the study aim, that is meaning units, were identified. (3) The meaning units were then condensed and labelled with codes, that is descriptive labels of the content of the condensed meaning units. (4) The codes were grouped based on differences and similarities, and three latent sub-themes were obtained. In the last steps, the sub-themes were seen to form an overarching theme. The sub-themes and the overall theme manifested the latent content that constituted the themes, that is the underlying meaning on an interpretative level of the text. Examples of the analysis process are shown in Table 2.

\section{Ethical considerations}

The Regional Ethical Review Board in Uppsala, Sweden, (Reg. no. 2015/203) approved the study. All participants were informed both in writing and verbally about the study aim and their rights to withdraw at any time and that their participation was anonymous. The participants gave their oral consent several times during the recruitment process and before the interview started. This consideration was made because dementia is by nature a memory disorder; therefore, the first consent cannot be

Table 2. Examples from the analysis process.

\begin{tabular}{|c|c|c|c|}
\hline Meaning unit & Condensed meaning unit & Code & Subtheme \\
\hline $\begin{array}{l}\text { Well, it is that they ... understand } \\
\text { me, and truly see me, so to say }\end{array}$ & They understand me and see me & $\begin{array}{l}\text { Seen and } \\
\text { understood }\end{array}$ & $\begin{array}{l}\text { Being seen as } \\
\text { a person }\end{array}$ \\
\hline $\begin{array}{l}\text { I mean, I don't want them to say what } \\
\text { I need to do. You want to have } \\
\text { what you need to decide for } \\
\text { yourself about how you want } \\
\text { things to be }\end{array}$ & $\begin{array}{l}\text { Don't say what I must do. } \\
\text { I want to be able to make } \\
\text { my own decisions }\end{array}$ & $\begin{array}{l}\text { Make your own } \\
\text { decisions }\end{array}$ & $\begin{array}{l}\text { Being informed } \\
\text { and involved }\end{array}$ \\
\hline $\begin{array}{l}\text { Because you want the same person, } \\
\text { so you can get to know them. It is } \\
\text { a basis. Because I think that I then } \\
\text { get to know them, and you can } \\
\text { then talk in another way. } \\
\text { Otherwise, you are unknown to } \\
\text { them when they come.... You } \\
\text { want to have someone you can } \\
\text { trust, and who you feel you can } \\
\text { trust }\end{array}$ & $\begin{array}{l}\text { Want the same staff to come } \\
\text { around so you can get to know } \\
\text { them and talk in another way. } \\
\text { You want someone you can } \\
\text { trust and who you feel you can } \\
\text { trust }\end{array}$ & $\begin{array}{l}\text { To have } \\
\text { a trusting } \\
\text { relationship }\end{array}$ & $\begin{array}{l}\text { Being part of } \\
\text { a relationship }\end{array}$ \\
\hline
\end{tabular}


considered valid on a later occasion (Hellstrom et al., 2007). Moreover, during the interviews, the first author once again asked for consent and observed non-verbal signs of inconvenience or indications of wishes to withdraw from the interviews (McKeown et al., 2010). If any such expression had occurred, the researcher would have interrupted the interview. However, no such situation occurred.

\section{Findings}

What older people with dementia experience as the important aspects of receiving HCS is illuminated by one theme - the importance of being supported as a unique and capable human - and includes three subthemes: being seen as a person, being informed and involved and being part of a relationship.

The importance of being supported as a unique and capable human meant that despite the participants' cognitive impairments, they expressed the importance of being met as a person with capabilities, although in need of support. The participants want to be treated as a unique individual with unique abilities and needs to be met. Their abilities were expressed when describing a wish to be involved in decisions and to be listened to despite their disabilities. The possibility of creating a relationship with the staff was considered important to being able to feel secure and to be seen as the persons they are, and it was also important that staff see them as an equal participant in the relationship.

\section{Being seen as a person}

The participants expressed the importance of being acknowledged and treated with respect as a unique human being not as one in the crowd. Being seen as a person included having their individual needs met so that they could continue to live their lives and manage their daily routines on their terms but with the support of the staff. The participants wanted to be recognised for who they were as individuals, and it was important for them not to be treated based on a general plan that was not adapted to their specific needs. Instead, they wished staff to see that they were all different from each other with different needs.

Yes, we are different humans. Sometimes we think alike. Commonly, we think unalike, but that is good.

The main thing is to be acknowledged for it. (Anna, 76)

The participants described that when the staff took time to be with them and listened to them, they felt treated with respect and confirmation, and they felt acknowledged, which was described as having a positive influence on their well-being and as a way to strengthen their self-esteem. Being seen as a person included a desire for staff to acknowledge them as "normal", that is as a person behind the diagnosis despite their difficulties.

Treat me as a human that still has sanity, if you know what I mean...Do not feel sorry for me. (Lisa, 84)

The participants also described the importance of being capable and that they wished the staff to support their ability, based on their individual preferences, to do as much as possible themselves, for example to do the household chores in their own way and at their own pace.

The participants stated that it was important to share the knowledge and skills they had achieved and developed over their lifetimes. They expressed a will to contribute with their knowledge and skills so that they could be useful in the care process and useful to other persons. When they had the opportunity to share their knowledge and were listened to by the staff, the participants explained that they felt recognised and valued and that their knowledge and life experiences could be of value. 
I think you should benefit from the patients. Take me for example, what can I do? Well, I can do quite a lot of specific things, even though they are few. However, I mean, I have general knowledge that I have applied throughout my life (Brian, 83)

\section{Being informed and involved}

The participants described the importance of being informed about their daily support, especially concerning changes in HCS that directly affect their daily life. For example the participants wanted to receive information about new staff and changes in the staff's schedule, that is whether the time of the staff visits would change. Furthermore, they also wanted to receive information about organisational changes that affected the staff's routines and how support was delivered, for example regarding personal activities such as baths/showers and tasks such as domestic cleaning. At times when the participants had not received information about changes in the HCS, they stated that it had the potential to cause them anxiety, and it left them feeling that they were unimportant.

The participants stated that they were sometimes not involved in decisions despite having made efforts to be involved. They stated that staff could even ignore their wishes and needs. When that happened, they commonly blamed themselves for being too demanding of the staff.

Well, I know that they are listening, but I do not know because then they do not seem to care. In addition, I do not want to keep nagging at them because I have told them once.... I can understand that they might think I have demands that are too great, and I do not have any paperwork about my rights and what they should do (George, 79).

When the participants were not listened to or were interrupted or corrected, they hesitated to express their preferences or wishes to be involved because they then felt as though their involvement was a greater burden for the staff. Sometimes conflicts could arise because the participants felt disrespected or ignored. One participant described the following:

Well, one time, I do not remember what we discussed exactly, but I did tell her what I wanted. She was so angry with me that she left me to take care of myself (Lisa, 84).

When this happened, the participants described a dissatisfaction with the support they received and the discomfort of being a burden.

\section{Being part of a relationship}

The relationship with the staff was described as generally positive and as a relationship dominated by friendliness and mutual respect, which contributed to a positive and uplifting friendship. This mutual relationship with the staff was an important aspect of HCS. The participants valued their relationships with the staff almost as much as their relationships with their true friends, where they could express their preferences. Furthermore, the participants stated that a relationship with the staff contributed to feelings of trust and made them feel relaxed during the staff's visit.

Because you want the same person, so you can get to know them. It is a basis. Because I think that I then get to know them, and you can then talk in another way. Otherwise, you are unknown to them when they come.... You want to have someone you can trust and who you feel you can trust (Christine, 83). 
Some participants said that they found it difficult to establish a personal relationship because of a lack of continuity. One participant returned to how sad she was at not being able to remember the different staff members' names and blamed herself.

I thought.... I was overreaching my capability. I thought 'Now I can remember them'. However, ....with all the different names... I cannot handle it anymore. Sometimes I recognise them. They say who they are, but I do not remember all of them (Mary, 84).

The participants also stated that they preferred it when staff were older and did not appreciate when the generation gap was extensive. When the staff were young, the participants stated that they found it difficult to have conversational 'talk'. The participants said they had more in common with older staff and shared the same fundamental values, which helped to build a relationship.

Well, I think you could say.... Those one experiences as.... I don't want to be insensitive, but it is like this when you are old, as I am...I mean if I am ninety and meet twenty-year-olds, it is a difference. We do not have the same experience at all! (Brian, 83)

\section{Discussion}

This study aimed to describe views on the important aspects of receiving HCS as described by persons with dementia. To our knowledge, this is the first study in which interviews were conducted with persons with dementia in the context of HCS. Our results highlight important aspects described by persons with dementia that need to be reflected upon by caregivers and care organisations. An older person's preferences and story are important when aiming to improve evidence-based practice (EBP), as care-users' expertise together with the latest research evidence and professionals' expertise serves as the foundation for EBP (Haynes 2002; Sackett et al. 1996).

Our findings emphasise, as summarised in the overarching theme, the importance of being supported as a unique and capable human, how crucial it is for an older person with dementia to be acknowledged and seen as a unique person with individual needs and capabilities, despite their disabilities, in relationships with staff. To be respected and seen by others as capable human beings are of the highest importance for all humans, as described in theories of PCC by Kitwood (1997). He further described that this is particularly important in the context of dementia because personal interactions may help or hinder a person's desire to maintain identity despite increasing cognitive impairment, which was also discussed in previous studies focussing on the identity of people with dementia (Batra et al., 2016; Brown Wilson, 2017; Hedman et al., 2018).

The participants in our study expressed the importance to their well-being of having a relationship with the staff that care for them, of being social, that is having reciprocal interactions with the staff, of being acknowledged through the context of where they live their life (their home) and of having their presence articulated and acknowledged by others; all of these observations are in line with theories of PCC (being in relationships, being in a social world, being in place and being oneself) described by McCormack and McCance (2016). However, to be able to work in a person-centred way, the staff need to have preparation to do so. In our study, the participants expressed that staff were more focussed on the tasks to be done than on genuinely acknowledging them as in a relationship, which is consistent with previous studies of dementia care (Jennings et al., 2019; Rapaport et al., 2018).

Szebehely and Trydegard (2012) explained this by suggesting that staff are pressured into a taskoriented approach by a too tight schedule and found that HCS has become more detail-oriented, 
leaving minimal time to nurture a relationship with the persons they care for. A detail-oriented task focus is in contrast to what the participants in our study stated, which suggests a more personalised approach. In addition, low continuity in staff results in a bad prerequisite for nurturing a relationship, and Schepens et al. (2019) found in a review that insufficient staffing, as well as high turnover, resulted in lower QoL for the persons receiving care. Thus, being able to practice PCC, where the relationship is a foundation, Karlsson et al. (2015), Schepens et al. (2019) and NBHW (2017) suggested that continuity in staff is important. Thus, the staff need to have resources from the HCS organisation to practice PCC, and they are expected to have the interest, knowledge and patience to create a relationship with persons with dementia.

There are several ways to create a relationship with persons with dementia and to work with the person's life story in daily practice. The use of the life story as a basis of care is considered a crucial component in PCC (Brown Wilson, 2017). Through the person with dementia telling their life story, staff are able to get to know them as a person on a deeper level (Fetherstonhaugh et al, 2013; Hansen et al., 2017). Thus, the life story of the person with dementia needs to be a foundation of developing a caring relationship between the person and the staff. A review by Elfrink et al. (2017) suggested that in a life story, the person's values and interests will be visible, which will enrich the care relationship. In turn, this may open lines of communication, deepen the relationship, enhance cooperation and moods, and improve the attitudes and knowledge of the caregiver. Berendonk and Caine (2019), as well as Cooney and O'Shea (2019), suggested that engaging in life story works enables staff to see the person behind the dementia, may change what staff consider important when delivering care according to the person's needs and interests and may work to facilitate a PCC approach.

In our study, the participants expressed a will to be recognised and valued for the skills, knowledge and experience they gained during their life. Being able to do so may strengthen one's sense of identity and may be a way to support pride in oneself and one's life, as McKeown et al. (2015) describe it. It could also, according to Kelly (2014), be seen as a way to recapture respect and be seen as equal to other persons. Thus, working with the person's life story is considered important, and as the participants in our study were able to describe their preferences, they would probably be able to contribute to communicating their life story. However, persons with dementia might have problems in doing so, and Cooney and O'Shea (2019) as well as Elfrink et al (2018) suggested that family or people who know the person with dementia may also contribute to life story work. However, there are several tools for helping to promote this work in interaction with the person with dementia, for example caregivers singing (Hammar et al., 2011; Swall et al., 2020) and studies with different kinds of reminiscence therapy, such as using photographs or musical activities (Woods et al., 2018).

Furthermore, the persons with dementia in our study expressed the fundamental need and desire to be informed and involved in decisions about their daily care, particularly the changes that affected their daily life. Not being involved in decisions was considered negative by the participants and can be perceived as them losing control over their daily life, as described in previous studies (Górska et al., 2013; Miller et al., 2016). Miller et al. (2016) found in their review that persons with dementia seldom participate in decisions about their care, that shared decisions are commonly not applied and that organisations need to work to improve this. In Sweden, the aim of social care is regulated in the Social Service Act (SFS 2001:453), which expresses a particular perception of what it is to lead a good life; this perception includes components such as meaningfulness and active participation in community life. It is also stated in the Swedish national fundamental values for care for older people that a person's needs, values and desires related to care should be the focus. Thus, enhancing shared decision-making in the care of persons with dementia should be a priority in 
improving PCC that is also regulated by law and national guidelines. To focus further on shared decision-making, persons with dementia should be involved on an organisational and national level in developing dementia care and not only participate in shared decision-making concerning their individual care.

Working in line with PCC and with persons with dementia is a complex task that urges education. In a Swedish context, the majority of staff lack education in caring for persons with dementia (Hallberg et al., 2016; Jennings et al., 2019; NBHW, 2017). In fact, in nursing homes for persons with dementia and in HCS, nursing aids provide the most care, and these professionals have little or no education in dementia care and possibly no formal training at all (Bing-Jonsson et al., 2016; Hallberg et al., 2016; NBHW, 2017). Consequently, the staff that are now working in HCS with persons with dementia are urged to take a greater responsibility for care than they are actually qualified to do. Bing-Jonsson et al. (2016) suggested that the lack of knowledge is probably the main reason that staff in dementia care have difficulty managing demanding care situations and encountering persons with dementia in a positive way, which could be one reason that the participants in our study stated that the staff sometimes had a bad attitude towards them.

In summation, the overarching theme - the importance of being supported as a unique and capable human - is not surprising compared to previous results that describe what older persons without dementia consider important. For example studies show that older persons without dementia value the staff treating them with respect and recognising them as an individual with individual needs (Breitholtz et al., 2013; Larsen et al., 2016). Having an interpersonal relationship with the staff is also important for older persons without dementia when receiving HCS (Jarling et al., 2018). Older persons without dementia value having accessible and respectful services that support their independence and that they have some control over (Dow et al., 2013). Thus, persons with dementia have, despite their dementia-related symptoms, similar feelings and values to persons without dementia. Thus, everyone who cares for older persons, with or without dementia, should see them as unique individuals with unique needs and should therefore treat them with respect and dignity, as with all other humans.

\section{Methodological considerations}

This study has some limitations. We asked the participants about their experiences with important aspects of HCS. Several of them may have had contact with staff from HHC, such as registered nurses, who were not employed by the HCS but were visiting the older person in their home. The participants may have had problems distinguishing the two different staff groups. Even though the majority of staff in their home were from HCS, the described experiences in this study may also have been influenced by experiences with staff outside HCS. The interviews varied in richness and length, and the meaning of the participants' answers sometimes needed to be clarified repeatedly due to their dementia. Obtaining long and rich descriptions cannot be expected when interviewing persons with dementia. However, the interviewer used an interview guide and posed probing questions, in addition to rephrasing the questions if the person seemed to have difficulty understanding. To illuminate the results, quotes are presented to illustrate the persons' descriptions. Trustworthiness was also increased by analysing data systematically using qualitative content analysis (Graneheim \& Lundman, 2004), which also helped in structuring the text. The analysis method also gave the researchers the opportunity to move back and forth between different levels of abstraction before reaching the latent level presented in the findings section. Trustworthiness was increased by performing the analysis in cooperation with other co-authors who, together, critically discussed the analysis steps conducted by MO and LMH. The capacity to consent to participation 
was first determined by the unit manager and the staff at the day-care centre, and as the manager was the one asking for interest in participation, there is a possibility that the participants may felt compelled to participate as the manager was the one responsible for their care at the day care centre. However, the manager was instructed to not pressurise people into taking part in the study and to observe for any signs of unwillingness to participate. In addition, the oral and written information included that if the participant did not want to participate or did withdraw their participation, it would not affect the care or service they received. The interviewer did also carefully identify whether the participants understood the information given and were able to decide to participate. Furthermore, had the interviewer observed non-verbal signs of unwillingness to participate or indications of other inconveniences, the researcher would have interrupted the interview. The participants in this study had the opportunity to receive information about the study. Additionally, they continuously had the opportunity to negotiate their consent. The first author is a nurse specialising in care for older people and has a long clinical history of working with people with dementia and their relatives, which contributed to an attentive and sensitive approach during the interviews.

\section{Conclusion}

Our study showed that persons with dementia are able to express, formulate and reflect on their needs and preferences about their daily care and on what is important to them when receiving HCS. Their views were congruent with the considerations involved in evidence-based PCC. Therefore, their point of view should be taken into consideration when planning, providing and evaluating care. Thus, persons with dementia need to be involved in research to a greater extent and have more opportunities to express their unique perspectives as a basis for developing high-quality dementia care.

\section{Author Contributions}

Study design: Marie Olsen, Anne-Marie Boström, Camilla Udo, and Lena Marmstål Hammar; data collection: Marie Olsen; analysis: Marie Olsen, Anne-Marie Boström, Camilla Udo, and Lena Marmstål Hammar; drafting of the manuscript: Marie Olsen, Anne-Marie Boström, Camilla Udo, and Lena Marmstål Hammar.

\section{Declaration of Conflicting Interests}

The authors declared no potential conflicts of interest with respect to the research, authorship, and/or publication of this article.

\section{Funding}

The authors received no financial support for the research, authorship, and/or publication of this article.

\section{Ethical Approval}

The Regional Ethical Review Board in Uppsala, Sweden, (Reg. no. 2015/203) approved the study.

\section{ORCID iD}

Lena Marmstål Hammar (D) https://orcid.org/0000-0003-2511-9502 


\section{References}

Batra, S., Sullivan, J., Williams, B. R., \& Geldmacher, D. S. (2016). Qualitative assessment of self-identity in people with advanced dementia. Dementia, 15(5), 1260-1278. DOI: 10.1177/1471301215601619.

Berendonk, C., \& Caine, V. (2019). Life story work with persons with dementia in nursing homes: A Grounded Theory study of the perspectives of care staff. Dementia, 18(1), 282-302. DOI: 10.1177/ 1471301216669236.

Bing-Jonsson, P. C., Hofoss, D., Kirkevold, M., Bjørk, I. T., \& Foss, C. (2016). Sufficient competence in community elderly care? Results from a competence measurement of nursing staff. BMC Nursing, 15, 5. DOI: 10.1186/s12912-016-0124-z.

Black, B. S., Johnston, D., Leoutsakos, J., Reuland, M., Kelly, J., Amjad, H., Davis, K., Willink A., Sloan D., Lyketsos C., \& Samus Q. M. 2019). Unmet needs in community-living persons with dementia are common, often non-medical and related to patient and caregiver characteristics. International Psychogeriatrics, 31(11), 1643-1654. DOI: 10.1017/s1041610218002296.

Bökberg, C., Ahlström, G., Leino-Kilpi, H., Soto-Martin, M. E., Cabrera, E., Verbeek, H., Saks, K., Stephan A., Sutcliffe C., \& Karlsson S. (2015). Care and service at home for persons with dementia in Europe. Journal of Nursing Scholarship, 47(5), 407-416. DOI: 10.1111/jnu.12158.

Breitholtz, A., Snellman, I., \& Fagerberg, I. (2013). Living with uncertainty: Older persons lived experience of making independent decisions over time. Nursing Research and Practice, 2013, 1. DOI: 10.1155/2013/ 403717.

Brown Wilson, C. (2017). Caring for people with dementia: A shared approach. Sage Publications.

Cooney, A., \& O'Shea, E. (2019). The impact of life story work on person-centred care for people with dementia living in long-stay care settings in Ireland. Dementia, 18(7-8), 2731-2746. DOI: 10.1177/ 1471301218756123.

Dow, B., Sparrow, P., Moore, K., Gaffy, E., \& Yates, I. (2013). What do older Australians want? Australasian Journal on Ageing, 32(4), 236-240. DOi: 10.1111/ajag.12040.

Elfrink, T. R., Zuidema, S. U., Kunz, M., \& Westerhof, G. J. (2017). The effectiveness of creating an online life story book on persons with early dementia and their informal caregivers: A protocol of a randomized controlled trial. BMC Geriatrics, 17(1), 95. DOI: 10.1186/s12877-017-0471-y.

Elfrink, T. R., Zuidema, S. U., Kunz, M., \& Westerhof, G. J. (2018). Life story books for people with dementia: A systematic review. International Psychogeriatrics, 30(12), 1797-1811. DOI: 10.1017/ s1041610218000376.

Fetherstonhaugh, D., Tarzia, L., \& Nay, R. (2013). Being central to decision making means I am still here!: The essence of decision making for people with dementia. Journal of Aging Studies, 27(2), 143-150. DOI: 10. 1016/j.jaging.2012.12.007.

Górska, S., Forsyth, K., Irvine, L., Maciver, D., Prior, S., Whitehead, J., Flockhart, J., Fairnie J., \& Reid J. 2013). Service-related needs of older people with dementia: Perspectives of service users and their unpaid carers. International Psychogeriatrics, 25(7), 1107-1114. DOI: 10.1017/s1041610213000343.

Government Preposition (2009/10):116. (2010). Värdigt liv i äldreomsorgen. In English: Wothy life in the care of older persons. Ministry of Social Affairs. Retrieved from: https://www.regeringen.se/49bbd8/contentassets/ 375c5289fb3b434b8aba108a38d6e1 f4/vardigt-liv-i-aldreomsorgen-prop.-200.

Graneheim, U. H., \& Lundman, B. (2004). Qualitative content analysis in nursing research: Concepts, procedures and measures to achieve trustworthiness. Nurse Education Today, 24(2), 105-112. DOI: 10.1016/j. nedt.2003.10.001.

Hallberg, I. R., Cabrera, E., Jolley, D., Raamat, K., Renom-Guiteras, A., Verbeek, H., Soto, M., Stolt M., \& Karlsson S. (2016). Professional care providers in dementia care in eight European countries; their training and involvement in early dementia stage and in home care. Dementia, 15(5), 931-957. DOI: 10.1177/ 1471301214548520.

Hammar, L. M., Emami, A., Engström, G., \& Götell, E. (2011). Communicating through caregiver singing during morning care situations in dementia care. Scandinavian Journal of Caring Sciences, 25(1), 160-168. DOI: $10.1111 / \mathrm{j} .1471-6712.2010 .00806 . x$. 
Hansen, A., Hauge, S., \& Bergland, Å. (2017). Meeting psychosocial needs for persons with dementia in home care services - A qualitative study of different perceptions and practices among health care providers. $B M C$ Geriatrics, 17(1), 211. DOI: 10.1186/s12877-017-0612-3.

Harrison, K. L., Ritchie, C. S., Patel, K., Hunt, L. J., Covinsky, K. E., Yaffe, K., \& Smith, A. K. (2019). Care settings and clinical characteristics of older adults with moderately severe dementia. Journal of the American Geriatrics Society, 67(9), 1907-1912. DOI: 10.1111/jgs.16054.

Haynes, R. B. (2002). What kind of evidence is it that evidence-based medicine advocates want health care providers and consumers to pay attention to? BMC Health Services Research, 2, 3. DOI: 10.1186/14726963-2-3.

Health and Medical Services Act (SFS 2017:30). Swedish: Hälso- ochsjukvårdslag (SFS 1982:763) Stockholm: Socialdepartementet. Retrieved from: https://www.riksdagen.se/sv/dokument-lagar/dokument/svenskforfattningssamling/halso-och-sjukvardslag_sfs-2017-30

Hedman, R., Hellström, I., Ternestedt, B.-M., Hansebo, G., \& Norberg, A. (2018). Sense of Self in Alzheimer's research participants. Clinical Nursing Research, 27(2), 191-212. DOI: 10.1177/1054773816672671.

Hellström, I., Nolan, M., Nordenfelt, L., \& Lundh, U. (2007). Ethical and methodological issues in interviewing persons with dementia. Nursing Ethics, 14(5), 608-619. DOI: 10.1177/0969733007080206.

Jarling, A., Rydström, I., Ernsth-Bravell, M., Nyström, M., \& Dalheim-Englund, A.-C. (2018). Becoming a guest in your own home: Home care in Sweden from the perspective of older people with multimorbidities. International Journal of Older People Nursing, 13(3), e12194. DOI: 10.1111/opn.12194.

Jennings, L. A., Turner, M., Keebler, C., Burton, C. H., Romero, T., Wenger, N. S., \& Reuben, D. B. (2019). The effect of a comprehensive dementia care management program on end-of-life care. Journal of the American Geriatrics Society, 67(3), 443-448. DOI: 10.1111/jgs.15769.

Karlsson, S., Bleijlevens, M., Roe, B., Saks, K., Martin, M. S., Stephan, A., Suhonen, R., Zabalegui A., \& Hallberg I. R. 2015). Dementia care in European countries, from the perspective of people with dementia and their caregivers. Journal of Advanced Nursing, 71(6), 1405-1416. DOI: 10.1111/jan.12581.

Kelly, F. (2014). Bodywork in dementia care: Recognising the commonalities of selfhood to facilitate respectful care in institutional settings. Ageing and Society, 34(6), 1073-1090. DOI: 10.1017/s0144686x13000093.

Kerpershoek, L., de Vugt, M., Wolfs, C., Woods, B., Jelley, H., Orrell, M., Stephan, A., Bieber A., Meyer G., Selbaek G., Handels R., Wimo A., Hopper L., Irving K., Marques M., Gonçalves-Pereira M., Portolani E., Zanetti O., \& Verhey F. (2018). Needs and quality of life of people with middle-stage dementia and their family carers from the European actifcare study. When informal care alone may not suffice. Aging \& Mental Health, 22(7), 897-902. DOI: 10.1080/13607863.2017.1390732.

Kitwood, T. (1997). Dementia reconsidered: The person comes first. Open University Press.

Larsen, L. S., Normann, H. K., \& Hamran, T. (2016). Continuity of home-based care for persons with dementia from formal and family caregivers' perspective. Dementia, 18, 846-863. DOI: 10.1177/1471301216682626.

Manthorpe, J., \& Samsi, K. (2016). Person-centered dementia care: Current perspectives. Clinical Interventions in Aging, 11, 1733-1740. DOI: 10.2147/cia.s104618.

Mazurek, J., Szcześniak, D., Urbańska, K., Dröes, R.-M., Karczewski, M., \& Rymaszewska, J. (2019). Does the meeting centres support programme reduce unmet care needs of community-dwelling older people with dementia? A controlled, 6-month follow-up polish study. Clinical Interventions in Aging, 14, 113-122. DOI: 10.2147/cia.s185683.

McCance, T, McCormack, B, \& Dewing, J (2011). An exploration of person-centredness in practice. Online Journal of Issues in Nursing, 16(2), 1. DOI: 10.3912/OJIN.Vol16No02Man01.

McCormack, B. (2016). Person-centredness and fundamentals of care - dancing with beauty rather than fighting ugliness. Canadian Journal of Nursing Leadership, 29(1), 17-25. Retrieved from http://proxy.kib.ki.se/login? url=http://search.ebscohost.com/login.aspx?direct=true\&db=cin20\&AN=118681097\&site=ehost-livec

McCormack, B., \& McCance, T. (2016). Person-centred practice in nursing and health care: Theory and practice. John Wiley \& Sons.

McKeown, J., Clarke, A., Ingleton, C., \& Repper, J. (2010). Actively involving people with dementia in qualitative research. Journal of Clinical Nursing, 19(13-14), 1935-1943. DOI: 10.1111/j.1365-2702.2009. 03136.x. 
McKeown, J., Ryan, T., Ingleton, C., \& Clarke, A. (2015). 'You have to be mindful of whose story it is': The challenges of undertaking life story work with people with dementia and their family carers. Dementia, 14(2), 238-256. DOI: 10.1177/1471301213495864.

Miller, L. M., Whitlatch, C. J., \& Lyons, K. S. (2016). Shared decision-making in dementia: A review of patient and family carer involvement. Dementia, 15(5), 1141-1157. DOI: 10.1177/1471301214555542.

Morbey, H., Harding, A. J. E., Swarbrick, C., Ahmed, F., Elvish, R., Keady, J., Williamson, P. R., \& Reilly S. T. (2019). Involving people living with dementia in research: an accessible modified Delphi survey for core outcome set development. Trials, 20(1), 12. DOI: 10.1186/s13063-018-3069-6.

Morrisby, C., Joosten, A., \& Ciccarelli, M. (2018). Do services meet the needs of people with dementia and carers living in the community? A scoping review of the international literature. International Psychogeriatrics, 30(1), 5-14. DOI: 10.1017/s1041610217001491.

National Board of Health and Welfare (NBHW). (2017). Nationella riktlinjer för vård och omsorg vid demenssjukdom - Stöd för styrning och ledning. National Board of Health and Welfare. In English: National guidelines for care and care in dementia - Support for governance and management. Retrieved from https:// www.socialstyrelsen.se/globalassets/sharepoint-dokument/artikelkatalog/nationella-riktlinjer/2017-12-2.pdf

Patient Safety Act (2010). Patient Safety Act (SFS 2010:659). In Swedish: Patientsäkerhetslag. Riksdagen. Retrieved from: https://www.riksdagen.se/sv/dokument-lagar/dokument/svensk-\%20forfattningssamling/ patientsakerhetslag-2010659_sfs-2010-659

Polit, D., \& Beck, C. (2016). Nursing research; generating and assessing evidence for nursing practice (10th ed.). Wolters Kluwer Health/Lippincott Williams \& Wilkins.

Rapaport, P., Livingston, G., Hamilton, O., Turner, R., Stringer, A., Robertson, S., \& Cooper, C. (2018). How do care home staff understand, manage and respond to agitation in people with dementia? A qualitative study. Bmj Open, 8(6), e022260. DOI: 10.1136/bmjopen-2018-022260.

Ruggiano, N., \& Edvardsson, D. (2013). Person-centeredness in home- and community-based long-term care: current challenges and new directions. Social Work in Health Care, 52(9), 846-861. DOI: 10.1080/ 00981389.2013 .827145$.

Sackett, D. L., Rosenberg, W. M. C., Gray, J. A. M., Haynes, R. B., \& Richardson, W. S. (1996). Evidence based medicine: What it is and what it isn't. BMJ, 312(7023), 71-72. DOI: $10.1136 / \mathrm{bmj} .312 .7023 .71$.

Sandberg, L., Nilsson, I., Rosenberg, L., Borell, L., \& Boström, A. M. (2019). Home care services for older clients with and without cognitive impairment in Sweden. Health \& Social Care in the Community, 27(1), 139-150. DOI: 10.1111/hsc.12631.

SBU [Swedish Agency for Health Technology Assessment and Assessment of Social Services] (2019). Kunskapsläget för bedömning och insatser inom äldreomsorgen. Identifiering av vetenskaplig kunskap och kunskapsluckor utifrån systematiska översikter. (SBU-rapport $n r$ 306. ). $\mathbf{m .}$. In English: The state of knowledge for assessment and action in the field of care for older persons. Identification of scientific knowledge and gaps in knowledge based on systematic overviews. Retrieved from Stockholm: https://www.sbu.se/306

Schepens, H. R. M. M., Van Puyenbroeck, J., \& Maes, B. (2019). How to improve the quality of life of elderly people with intellectual disability: A systematic literature review of support strategies. Journal of Applied Research in Intellectual Disabilities, 32(3), 483-521. DOI: 10.1111/jar.12559.

Schön, P., Lagergren, M., \& Kåreholt, I. (2016). Rapid decrease in length of stay in institutional care for older people in Sweden between 2006 and 2012: Results from a population-based study. Health \& Social Care in the Community, 24(5), 631-638. DOI: 10.1111/hsc.12237.

Social Services Act (SFS 2001:453). In Swedish: Socialtjänstlagen (SFS 2001:453).Ministry of Health and Social Affairs. Retrieved from http://www.riksdagen.se/sv/dokument-lagar/dokument/svenskforfattningssamling/socialtjanstlag-2001453_sfs-2001-453

SOSFS 2012:3. Värdegrunden i socialtjänstens omsorg om äldre. Socialstyrelsen [ National Board of Health and Welfare]. In English. The national fundamental values care for older persons. Retrieved from: https:// www.socialstyrelsen.se/globalassets/sharepoint-dokument/artikelkatalog/foreskrifter-och-allmanna-rad/ 2012-2-20.pdf 
Swall, A., Hammar, L. M., \& Gransjön Craftman $\AA$. (2020). Like a bridge over troubled water - A qualitative study of professional caregiver singing and music as a way to enable person-centred care for persons with dementia. International Journal of Qualitative Studies on Health and Well-being, 15(1), 1735092. DOI: 10. 1080/17482631.2020.1735092.

Szebehely, M., \& Trydegård, G.-B. (2012). Home care for older people in Sweden: A universal model in transition. Health \& Social Care in the Community, 20(3), 300-309. DOI: 10.1111/j.1365-2524.2011.01046.x.

Wiles, J. L., Leibing, A., Guberman, N., Reeve, J., \& Allen, R. E. S. (2012). The meaning of "aging in place" to older people. The Gerontologist, 52(3), 357-366. DOI: 10.1093/geront/gnr098.

Woods, B., O'Philbin, L., Farrell, E. M., Spector, A. E., \& Orrell, M. (2018). Reminiscence therapy for dementia. Cochrane Database of Systematic Reviews, 3(3), Cd001120. DOI: 10.1002/14651858. CD001120.pub3.

Marie Olsen is a doctoral student in nursing with a research focus on persons with dementia and home care service. She has a background as a Specialist Nurse in care for older adults and in teaching within the field of care for older adults and care for person with dementia. Ms. Olsen is engaged in improving care and support for persons with dementia and promoting their well-being by increasing the knowledge and understanding of caregivers regarding the desire of persons with dementia's need to be seen as a unique individuals.

Camilla Udo is an Associate Professor in Social Work focussing on communication, especially conversations on existential issues, between health care professionals and patients/care users in different contexts.

Anne-Marie Boström is an Associate Professor in Nursing with a focus on health and well-being for older persons with or without dementia. Dr. Boström is conducting research on the dissemination and implementation of research findings and evidence in the care of older adults.

Lena Marmstäl Hammar is an associate professor in Nursing. Dr. Hammar's latest research focusses on persons with dementia and their spouses and marital communication. She is currently a principal investigator in a project focussing on developing support for this group. She is also engaged in research on music and singing as nonpharmacological treatment for persons with dementia, as well as in research focussing on persons with dementia and home care service. 